\title{
Cross Language Differences in Aggression Between Japanese and English speakers
}

\author{
Yushi $\mathrm{Cao}^{1 *}$, Serena Chang ${ }^{2}$, Junzhe Song \\ ${ }^{1}$ School of Engineering, Zhejiang University, Hangzhou, Zhejiang 310000 \\ ${ }^{2}$ Loomis Chaffee school, United State \\ ${ }^{3}$ RDFZ King's College School Hangzhou, Hangzhou, Zhejiang 310000 \\ "Email:1254314297@qq.com; ${ }^{2}$ Serena_chang@loomis.org; ${ }^{3}$ song.junzhe@rkcshz.cn
}

\begin{abstract}
According to the Cultural Frame Switching phenomenon (CFS), individuals who identify with two or more different cultures change their view of the world and their mental states when they switch between different languages. The proposed study will use past research in order to create an experiment that can further prove the correlation between personality and language.In this paper, the objectives are testing whether Japanese individuals and American individuals differ in aggressiveness, testing on bilinguals who speak both Japanese and English, and determining whether speaking Japanese or English can cause an individual to become more aggressive.
\end{abstract}

Keywords: Cultural Frame Switching phenomenon, Bilinguals, personality, aggressive

\section{INTRODUCTION}

Although the idea of cross-language personality differences of an individual is widely considered, there are only a few studies that delve into the effect of changing the language spoken by an individual result in a change of the personality of that individual. The most relevant theory for this phenomenon is the Cultural Frame Switching Phenomenon (CFS). The CFS effect is where "bicultural individuals shift values and attributions in the presence of culture-relevant stimuli" [1]. One experiment conducted that provides support for the CFS effect found that between French and English speakers, the cross-language personality differences exist as a function of cultural shifts [2]. Ervin found that there was more verbal aggression in French stories in comparison to English stories. She believed that this was due to the fact that French education tended to emphasize standing up for yourself in an argument. Another study that supported the connection between shifts in language and shifts in personality is the study done by [3]. The results of Hull's experiment conducted on Spanish-English speakers showed that the bilinguals scored higher on the Good Impression factor when speaking Spanish compared to English, providing further evidence for the CFS phenomena.

The last experiment that this experiment will draw from will be the experiment conducted by Ramírez-Esparza et. al. (2006). The experiment was designed to test the validity of the CFS effect by studying Spanish-English bilinguals, in order to elucidate how their personalities changed when they spoke in Spanish versus English. The experiment found that the Spanish-English bilinguals were more extraverted, agreeable, and conscientious when speaking English compared to Spanish. This study proved that the CFS effect also existed for personality [1].

However, previous studies are still unable to completely confirm the CFS effect. In Hull's (1996) study, the method used for the experiment was criticized for lacking a factorial foundation. In Ervin's (1964) study, there was no clear comparative evidence. While the Ramírez-Esparza et al. (2006) experiment was successful in determining whether the CFS effect was found for personality, it could not be generalized to any other languages [1].

The proposed study plan on mirroring the method of the Ramírez-Esparza et al. (2006) experiment while changing the research group. In order to confirm that the CFS effect can be generalized to other languages, the study will use Japanese-English Bilinguals for this study. This study selected Japanese and American culture due to the relatively large differences in Japanese and English culture. In Japanese culture, "duty is considered 
to be more important than personal happiness" [4], which teaches Japanese people to be more selfless and to think of others before themselves. This is in contrast to cultural norms instilled by the American education system which stresses individual freedom and individual rights.

\section{PROPOSED STUDY 1: THE CONFIRMATION FOR EXPECTED PERSONALITY DIFFERENCES}

The first proposed study is designed to establish a baseline for aggressiveness of the general Japanese and American population, who presumably only speak one language - their native language.

According to previous studies, in contrast to the Western cultural norms, the Japanese tend to put their duty (towards family and society) before personal happiness due to the influences of Buddhism and Confucianism [4]. This first proposed study aims to discover and confirm that the cultural differences between Japanese and Americans cultural can cause different amounts of aggressiveness in their personalities, although the study will not be able to establish a strict causality between differences in cultural and differences in aggressiveness. Nonetheless, this first proposed study will establish the baseline for us to further evaluate the CFS phenomena, which is the main goal of this proposed study.

To deal with these questions, the research will use a large sample of individuals who live in Japan or the United States. In order to do so, the study will use online resources to collect large samples and analyze the test feedback [5]. This study will use the internet to disperse the Aggression Spectrum Test and collect data. This research will evaluate participants' personalities by analyzing the test feedback, which in turn can give us a more generalized scale of aggression for the general Japanese and American population.

\subsection{Method}

\subsubsection{Participants}

Participants are selected from volunteers recruited on the Internet. Only those who have indicated that they live in Japan or the United States and are between the ages of 18 and 60 are selected to be participants. Moreover, only those who have indicated that they had not taken the questionnaire previously are allowed to participate in the questionnaire [1]. Because gender will not influence the study, both male and females will be recruited.

\subsubsection{Procedure}

Selected participants are requested to visit the website www.idrlabs.com that contains the Aggression Spectrum Test in both English and Japanese, as well as diversions, tests, and other identity surveys. The participants will be asked to take the Aggression Sepctrum Test in their native languages, either Japanese or English, the information collection and scoring will be automated, giving participants quick feedback about their personalities. Both web pages have the same physical appearance, information, and questions. The only difference is the language of the questionnaire [1].

\subsection{Results and discussion}

\subsubsection{Behavioral outcome measurement}

When members click on "submit", they will receive a graph for their aggression profile, which is illustrated in Figure 1. Their final aggressiveness and verbal aggression will be recorded. Since the sample is expected to be very large, mean and standard deviations of the feedback data will be used to evaluate participants' aggression profile in aggregate.

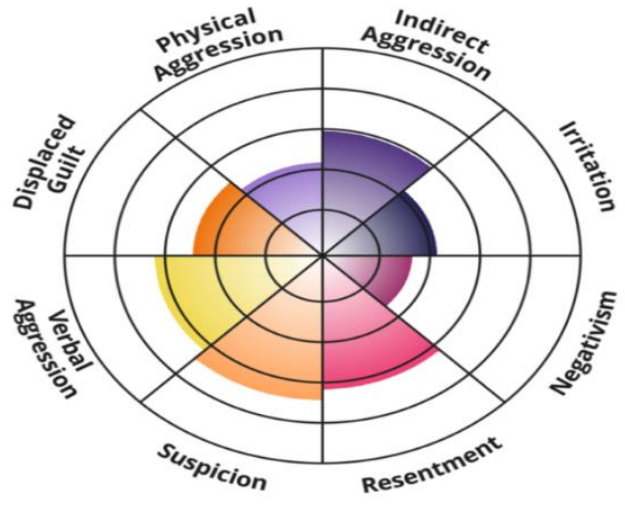

Your aggressiveness is moderate (54.38\%).

Figure. 1 The Feedback of the Aggression Spectrum Test [6]

\subsubsection{Predictions}

To decide whether different level of aggressiveness exists within the two cultures, participants' feedbacks are recorded in Table 1. It is generally believed that Japanese people tend to put their duty before personal happiness, while personal happiness is a top priority among Americans. Furthermore, the Japanese are taught to conceal their true thoughts and be polite. Therefore, Japanese verbal aggression and total aggressiveness are expected to be lower than those of Americans. 
Table 1. the Aggression Spectrum Test scores of Japanese-speakers in the Japan and English-speakers in the US (Illustrative)

\begin{tabular}{|l|l|l|l|l|}
\hline \multirow{2}{*}{ Factor } & \multicolumn{2}{l|}{ United State (English) } & \multicolumn{2}{l|}{ Japan (Japanese) } \\
\cline { 2 - 5 } & Mean & SD & Mean & \\
\hline Verbal Aggression & & & & \\
\hline $\begin{array}{l}\text { Final } \\
\text { Aggressiveness }\end{array}$ & & & & \\
\hline
\end{tabular}

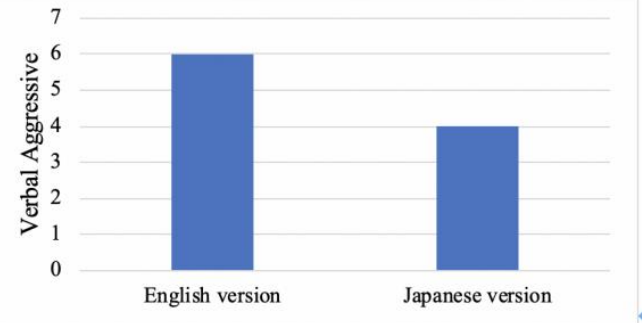

Samples

Figure 2. Mean verbal Aggressive scores in English and Japanese

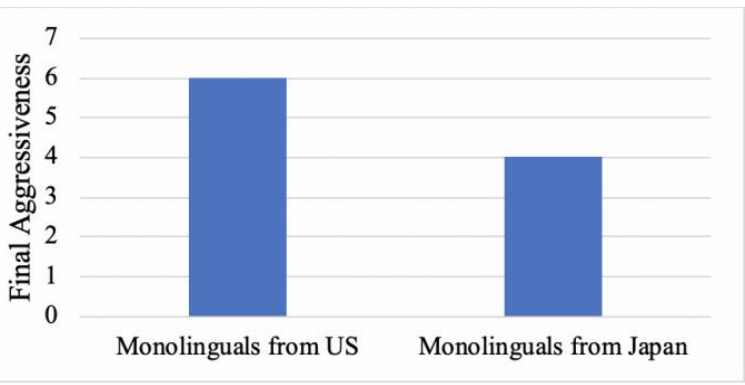

Samples

Figure 3. Mean Final Aggressiveness scores in English and Japanese

\section{PROPOSED STUDY 2: SHIFTS OF AGGRESSION LEVEL AMONG JAPANESE-ENGLISH BILINGUALS}

The proposed study 2 is designed to investigate whether Japanese-English Bilinguals will exhibit different level of aggressiveness, when the language of the questionnaire is changed from Japanese to English or vice versa. To deal with this question, this study uses the internet to disperse the questionnaires and collect data. This research will evaluate participants' verbal aggression by analyzing the test feedback.

\subsection{Method}

\subsubsection{Participants}

Participants are selected from volunteers recruited on the Internet. Only those who indicate that they live in
Japan or the United States and were between the ages of 18 and 60 were selected to be the participants. And the volunteers who were fully bilingual, with a deep understanding of both languages and indicated they had not taken the questionnaire before can participate this experiment [1].

More specifically, the study aims to recruit four groups of individuals:

Type I: people born in Japan later acquired English proficiency in Japan

Type II: people born in Japan and later acquired English proficiency in America

Type III: people born in America and later acquired Japanese proficiency in America

Type IV: people born in America and later acquired Japanese proficiency in Japan

\subsubsection{Measurement of bilingualism}

Before the experiment, volunteers were required to pass the bilingual language examination to prove their language ability. Only the volunteers who were fully bilingual, with a deep understanding of both languages can participate in this experiment. Participants have to fill out questionnaires in both English and Japanese where they had to determine the personality of fictional individuals. Participants receive the questionnaires by E-mail.

As Figure 4 shows, the questions are set in everyday life scenarios and have four everyday words options. The subjects are asked to choose which of four emotional and synonymous words they would use in these scenarios. Participants are asked to choose one option. Four words with different emotional colors will yield different points. For instance, in example 1, choice A will yield 2 points, choice B will yield 3 points, and choice $\mathrm{C}$ will yield 5 points, and choice $\mathrm{D}$ will yield 1 point. The total score of the questionnaire will be used as the evaluation criteria of participants' personalities. 
さんか買い物する時に、他人に割り込まれだもしあ なたが $\mathrm{A}$ さんだったら、割り込んだひとに対して、 こんな行為は「」

$\mathrm{A}$ 失礼です $\mathrm{B}$ 好ましくない $\mathrm{C}$ 思考をへっていま せん D 何も言わない

While simon was paying for his groceries, someone cut the line in front of him. If you were Simon, would you say: This type of behavior is

A. not right B. distasteful C. despicable D. Not say anything

Figure. 4 Sample question

\subsection{Results and Discussion}

\subsubsection{Behavioral outcome measurement}

When members click on the "submit", they will immediately receive their verbal aggression test feedbacks. Meanwhile, their final scores in the test are recorded. Since the sample is expected to be very large, mean and standard deviations of the feedback data will be used to evaluate participants' aggression level.

\subsubsection{Predictions}

To determine the difference in the aggression of Bilinguals, participants' feedbacks are recorded in Figure 5. In a previous study, it was found that there was more verbal aggression in French stories in comparison to English stories. This difference rests chiefly on the fact that French education tended to emphasize standing up for oneself in an argument. Furthermore, because Japanese-speakers and English-speakers have different cultural backgrounds, the study expect that similarly different pattern may exist among Japanese-English bilinguals. To be more specific, bilinguals may exhibit less aggressiveness when taking the questionnaire in Japanese.

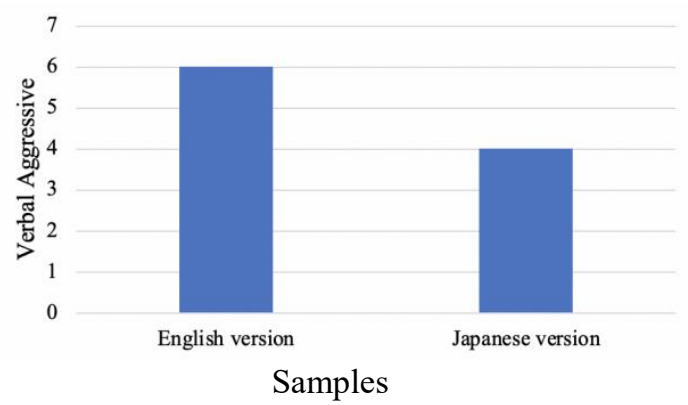

Figure 5. Mean Final Verbal Aggressive scores in Bilinguals

Furthermore, since the CFS effect is where "bicultural individuals shift values and attributions in the presence of culture-relevant stimuli", the study expect that when the "culture-relevant stimuli" is stronger, the study will see a larger shift in the aggressiveness level. This hypothesis could be confirmed by analyzing the type I-IV data and compare results from Type I and Type II, and results from Type III and Type IV.

The study expects that, bilinguals who are born in Japan and learned English in Japan may become more aggressive when speaking English, however, the extent of such change is less than those bilinguals who are born in Japan and learned English in America. This is because that the "culture-relevant stimuli" for the American culture is stronger in America than in Japan.

Likewise, the study expects that, bilinguals who are born in America and learned Japanese in America may become less aggressive when speaking Japanese, however, the extent of such change is less than those bilinguals who are born in America and learned Japanese in Japan. This is because that the "culture-relevant stimuli" for the Japanese culture is stronger in Japan than in America.

\section{CONCLUSION}

\subsection{Implication}

These findings have implications for future study. Studies have shown that during a long-term language switch, the thinking patterns and personality traits of foreign language learners will become closer to those of native speakers, and their cognitive and information processing patterns will be different. The acquisition of more than two foreign languages is of great benefit to the cognitive process. First, the use of a foreign language can significantly stimulate neurons and synapses in the gray matter of the brain, making its structure denser and exercising the brain. Second, vocabulary memorization and language switching can also effectively exercise memory and multitasking ability, as well as character building.

Studies should examine the extent to which these differences found in self-reports extend to observer judgments. What are the significant differences between English speakers and Japanese speakers, and do they become more polite when speaking Japanese? Future studies should consider the effect of environmental acculturation on CFS. Do more culturally attuned bilinguals experience larger (or smaller) personality changes when they change language? Does bilinguals' national self-identity mediate the transformation of different personalities?

Together, these efforts will provide a more detailed understanding of the mechanisms proposed in this study.

\section{REFERENCES}

[1] Ramírez-Esparza, N., Gosling, S. D., Benet-Martínez, V., Potter, J. P., \& Pennebaker, J. W. (2006). Do bilinguals have two personalities? A 
special case of cultural frame switching. Journal of Research in Personality, 40(2), 99-120.

[2] Ervin, S. M. (1964). Language and TAT content in bilinguals. Journal of Abnormal and Social Psychology, 68, 500-507.

[3] Hull, P. V. (1996). Bilingualism: Some personality and cultural issues. In D. I. Slobin, J. Gerhardt, A. Kyratzis, \& J. Guo (Eds.), Social interaction, social context, and language: Essays in honor of Susan Ervin-Tripp (pp. 419-434). New Jersey: Lawrence Erlbaum Associates.

[4] Vos, F. (1978). Background to Japanese Culture. The World of Music, 20(2), 61-63. Retrieved September 10 , 2021,

from http://www.jstor.org/stable/43563631

[5] Gosling, S. D., Vazire, S., Srivastava, S., \& John, O. P. (2004). Should we trust Web-based studies? A comparative analysis of six preconceptions about Internet questionnaires. American Psychologist, 59, 93- 104.

[6] A.Bass. The Aggression Test. Retrieved from https://www.idrlabs.com/aggression/test.php

[7] Hong, Y.-Y., Chiu, C.-Y., \& Kung, T. M. (1997). Bringing culture out in front: EVects of cultural meaning system activation on social cognition. In K. Leung, Y. Kashima, U. Kim, \& S. Yamaguchi (Eds.), Progress in Asian social psychology (Vol. 1, pp. 135-146). Singapore: Wiley. 